\title{
Применение тинростима для коррекции нарушений иммунитета и гемостаза в комплексном лечении пациентов с хронической обструктивной болезнью легких
}

1 - лаборатория иммунологии НИИ эпидемиологии и микробиологии СО РАМН: 690087, Владивосток, ул. Сельская, 1;

2 - кафедра госпитальной терапии с курсом фтизиопульмонологии ГОУ ВПО "Владивостокский государственный медицинский университет Росздрава":

690950, Владивосток, пр-т Острякова, 2

T.A.Kuznetsova, M.F.Kinyaikin, G.I.Sukhanova, N.N.Besednova

\section{Use of tinrostim for treatment of immune and hemostasis disorders as a part of combined therapy of patients with chronic obstructive pulmonary disease}

\begin{abstract}
Summary
The trial was aimed to evaluate effects of tinrostim, which is a complex of low molecular weight peptides, on immunity and hemostasis and to show its clinical efficacy in patients with acute exacerbation of chronic obstructive pulmonary disease (COPD). This randomized study of 108 patients showed that inclusion of tinrostim in the combined treatment improved the immune system resulting in normalization of cellular and humoral immunity (increase in numbers of $\mathrm{CD}^{+}-, \mathrm{CD}^{+}$-lymphocytes and complement components, decrease in concentrations of circulating immune complexes, serum TNF- $\alpha$, IL-6, and IL-10), and increase in phagocyte activity of neutrophil leukocytes. In patients received tinrostim, results of the ortofenantrolin test decreased from $21.4 \pm 2.5$ to $14.4 \pm 2.2 \mathrm{mg} / \%(p=0.026)$ and blood fibrinolytic activity increased from $6.9 \pm 0.59$ to $10.7 \pm 1.6 \%(p=0.037)$ that could be a sign of resolution of disseminated intravascular coagulation and prevention of fibrosis in the bronchial tree. Clinical effect of Tinrostim were seen as an improvement in symptoms such as cough $(p<0.02)$ and dyspnea $(p<0.05)$ and in the lung ventilation (increase in $\left.\mathrm{FEV}_{1}\right)(p<0.05)$.

Key words: immunity, hemostasis, chronic obstructive pulmonary disease.
\end{abstract}

\section{Резюме}

Целью исследования стала оценка влияния тинростима (комплекса низкомолекулярных пептидов) на систему иммунитета и гемостаза и его клинической эффективности у пациентов с обострением хронической обструктивной болезни легких. В рандомизированном исследовании 108 больных показано, что включение тинростима в состав комплексной терапии оказывает корригирующий эффект на состояние иммунной системы: нормализуются показатели клеточного и гуморального иммунитета (повышается содержание $\mathrm{CD}^{+}-$, $\mathrm{CD}^{+}$-лимфоцитов и уровня компонентов комплемента, снижается концентрация циркулирующих иммунных комплексов и провоспалительных цитокинов в сыворотке крови), усиливается фагоцитарная активность нейтрофильных лейкоцитов. Под влиянием тинростима снижались показатели ортофенантролинового теста (с $21,4 \pm 2,5$ до $14,4 \pm 2,2$ мг/\%; $p=0,026)$ и возрастала фибринолитическая активность крови (с $6,9 \pm 0,59$ до $10,7 \pm 1,6 \% ; p=0,037)$, что свидетельствует о купировании внутрисосудистого свертывания крови и способствует предотвращению процессов фиброзирования в бронхиальном дереве. Клинический эффект исследуемого препарата проявлялся в уменьшении выраженности основных симптомов заболевания: кашля $(p<0,02)$ и одышки $(p<0,05)$, улучшении вентиляционной функции легких (увеличение показателей объема форсированного выдоха за 1-ю с; $p<0,05$ ).

Ключевые слова: иммунитет, гемостаз, коррекция, хроническая обструктивная болезнь легких.

Широкое распространение во всем мире хронической обструктивной болезни легких (ХОБЛ) делает проблему ее лечения и профилактики одной из наиболее актуальных. В частности, поиск и разработка новых препаратов, усиливающих эффективность патогенетической терапии при ХОБЛ, составляют важное направление современной медицины [1, 2].

В связи с тем, что в патогенезе ХОБЛ имеет место вторичная иммунологическая недостаточность, затрагивающая различные звенья иммунитета, в составе комплексной терапии показано использование иммунокорректоров. Широко применяются препараты полипептидной природы. В частности, тактивин, тималин, вилон у больных ХОБЛ оказывали выраженный клинический эффект, нормализуя показатели иммунитета [3, 4].
Патология системы гемостаза при ХОБЛ проявляется внутрисосудистым свертыванием крови, что связано с поступлением из тканей в кровь стимуляторов свертывания и активаторов агрегации тромбоцитов, повреждением эндотелия сосудов токсинами, иммунными комплексами, продуктами клеточного распада. Лабораторные признаки нарушения в системе гемостаза - гиперкоагуляция крови и гиперфибриногенемия.

Маркерами внутрисосудистого свертывания крови, имеющими большое диагностическое значение при ХОБЛ, служат растворимые фибрин-мономерные комплексы и продукты деградации фибрина [5, 6]. Характерными признаками являются активация и истощение компонентов свертывающей и фибринолитической систем [7, 8]. 
Существуют многочисленные примеры использования в клинической практике полипептидов природного и синтетического происхождения для коррекции не только нарушений в системе иммунитета, но и в системе гемостаза при различных заболеваниях [9, 10].

Цель данного исследования - оценить влияние тинростима на систему иммунитета и гемостаза и показать его клиническую эффективность у больных с обострением ХОБЛ.

Тинростим как иммунокорректор достаточно широко применяется в виде биологически активной добавки к пище при лечении различных бактериальных и вирусных инфекций, онкогематологических, соматических и других заболеваний [11]. Влияние этого пептида на систему гемокоагуляции ранее не исследовалось. В настоящее время тинростим находится на стадии предклинических испытаний для создания на его основе лекарственной формы. Разработана технология получения лекарственной формы для внутримышечного введения, и выпущена опытная партия для клинических испытаний.

\section{Материалы и методы}

Обследованы 108 больных с обострением ХОБЛ средней и тяжелой степени, находившихся в отделении пульмонологии краевой клинической больницы. Средний возраст пациентов составил 67,3 $\pm 2,4$ года. Всех включенных в обследование больных рандомизировали методом случайной выборки на однородные, сопоставимые по возрасту и клинической картине группы. Формирование групп испытуемых проводили с учетом принципов доказательной медицины. Постановку диагноза и оценку степени тяжести осуществляли на основании анамнеза, общеклинических, функциональных (состояние функции внешнего дыхания) и лабораторных методов обследования, согласно рекомендациям GOLD [2].

Базисная терапия больных включала в себя стандартные средства для лечения обострения ХОБЛ: глюкокортикостероиды (преднизолон, дексаметазон), бронходилататоры (сальбутамол, ипратропиума бромид), антибиотики широкого спектра действия (ампициллин, цефалоспорины, макролиды, респираторные фторхинолоны).

С целью оценки эффективности применения тинростима пациенты были поделены на 2 группы. В 1-ю группу (основную) вошли больные, которые помимо базисного курса лечения принимали тинростим. Вторую группу (сравнения или контрольная) составили пациенты, которые получали аналогичный курс терапии без тинростима (базисная терапия). Обследование проводили до и по окончании курса лечения. От каждого испытуемого получали добровольное информированное согласие, что регистрировали в специальной карте. Также обследовали группу практически здоровых лиц (25 доноров краевой станции переливания крови), не имеющих хронической бронхолегочной патологии и аллергических заболеваний (показатели которых принимали за среднее значение нормы).
Тинростим назначали по 1 таблетке 2 раза в день до еды утром и вечером в комплексе с базисной терапией, курс приема - 15 дней. Действующее вещество тинростим представляет собой комплекс низкомолекулярных пептидов, выделенных из оптических ганглиев кальмаров промысловых видов. Тинростим разрешен к производству, реализации и применению на территории РФ (регистрационное удостоверение № 77.99.04.928.Б.000663.08.03 от 29.08.03).

В комплекс лабораторного обследования помимо общеклинических методов включали оценку параметров иммунной системы: показателей клеточного звена иммунного ответа (общее число лейкоцитов и лимфоцитов периферической крови и их субпопуляционный состав, иммунорегуляторный индекс $\mathrm{CD}^{+}{ }^{-}$/ $\mathrm{CD}^{+}-$), фагоцитарный показатель (в \%) и фагоцитарное число (ФЧ в у. е.) нейтрофилов. Изучали также показатели гуморального иммунитета: спектр про- и противовоспалительных цитокинов, компонентов комплемента, уровень циркулирующих иммунных комплексов (ЦИК), содержание иммуноглобулинов в сыворотке крови. Кроме того, исследовали параметры коагулограммы, позволяющие судить о состоянии плазменного звена гемостаза: тромбиновое время, протромбиновый индекс; маркеры тромбинемии: ортофенантролиновый тест (ФТ); содержание естественных антикоагулянтов; уровень антитромбина III, а также фибринолитическую активность крови (ФА) и уровень фибриногена.

Клиническую эффективность оценивали после лечения по проявлению основных симптомов: кашля и одышки (по 4-балльной шкале), продолжительности показателей общей слабости, потливости, субфебрильной температуры (в днях), а также по показателю вентиляционной функции легких - объему форсированного выдоха за 1-ю с $\left(\mathrm{OФB}_{1}, \%_{\text {долж.). }}\right.$

Данные представлены как $M \pm m$, критическое значение уровня значимости принималось равным $5 \%(p<0,05)$. Оценка значимости различий при нормальном распределении проводилась с использованием t-критерия Стьюдента (для независимых выборок и для попарно связанных вариационных рядов). При ненормальном распределении количественных признаков применяли непараметрический $\mathrm{W}$-критерий Вилкоксона (для сравнения показателей до и после лечения или 2 попарно связанных показателей). Наличие взаимосвязей показателей оценивали посредством коэффициента ранговой корреляции Спирмена (r).

\section{Результаты и обсуждение}

Результаты исследования состояния иммунной системы больных ХОБЛ до лечения свидетельствуют о нарушении клеточных (снижение содержания общей и регуляторных субпопуляций Т-лимфоцитов) и гуморальных (повышение уровня $\operatorname{IgM}$ и снижение $\mathrm{IgA}$, повышение концентрации ЦИК, дефицит С3-, C4-, C5-компонентов комплемента, существенное превышение нормального содержания про- и противовоспалительных цитокинов в сыворотке крови) 
механизмов иммунитета у больных ХОБЛ, по сравнению со здоровыми. Показатели фагоцитарной активности нейтрофильных лейкоцитов крови у пациентов с ХОБЛ также были снижены.

Из числа обследованных больных ХОБЛ нарушения в системе гемостаза, характерные для латентного внутрисосудистого свертывания, были выявлены в $57 \%$ случаев. До лечения значения ФТ - наиболее информативного и стандартизованного показателя течения диссеминированного внутрисосудистого свертывания, выявляющего циркуляцию в крови активного тромбина и растворимых фибрин-мономерных комплексов, значительно превышали таковые у здоровых лиц $(20,1 \pm 2,4$ мг/\% у больных ХОБЛ и 3,38 \pm 0,39 мг $/ \%$ у здоровых; $p=0,001)$. Кроме того, у пациентов с ХОБЛ вдвое снижались показатели ФА $(6,9 \pm 0,59 \%$ и $14,0 \pm 2,1 \%$ соответственно; $p=0,001)$, что свидетельствует об угнетении фибринолитической активности крови и является прогностически неблагоприятным признаком, т. к. способствует отложению избытка фибрина, являющегося матрицей для фибробластов, и ведет к формированию фиброза.

В связи с тем, что иммунные механизмы имеют особое значение в регуляции системы гемостаза, в ряде работ показано, что нарушения в иммунной системе коррелируют с таковыми в системе гемостаза при различных заболеваниях [9, 10, 12, 13]. Было проведено исследование подобных взаимосвязей у пациентов с ХОБЛ между исходными (до лечения) показателями Т-клеточного звена иммунитета, цитокинового статуса и показателями системы гемостаза, характерными для латентного синдрома диссеминированного внутрисосудистого свертывания крови. Установлена прямая значимая тесная связь уровня фактора некроза опухоли- $\alpha$ (TNF- $\alpha)$ с ФТ ( $r=0,816$; $p=0,006)$, умеренная связь уровня интерлейкина-6 (IL-6) с ФТ $(r=0,676 ; p=0,004)$ и обратная слабая связь между содержанием $\mathrm{CD}^{+}$-лимфоцитов и показателями ФТ $(r=-0,234 ; p=0,017)$. Взаимосвязь уровня цитокинов в сыворотке крови с ФА у больных ХОБЛ представляла собой обратную умеренную корреляцию с уровнем ТNF- $\alpha(r=-0,489 ; p=0,05)$ и с уровнем IL-6 $(r=-0,416 ; p=0,04)$. Кроме того, выявлена умеренная прямая корреляционная связь между содержанием CD3 ${ }^{+}$-лимфоцитов и показателями ФА $(r=0,423 ; p=0,024)$. Для остальных показателей корреляционные взаимосвязи либо не были установлены, либо были статистически незначимы.

Включение тинростима в курс лечения проводило к повышению, по сравнению с исходным значением, относительного содержания $\mathrm{CD}^{+}$-лимфоцитов до $60,9 \pm 3,13 \%(p=0,01)$, тогда как у больных 2-й группы оно лишь имело тенденцию к увеличению. У пациентов, принимавших тинростим, также увеличивалось содержание $\mathrm{CD}^{+}$-лимфоцитов $(p=0,01)$. Выраженное стимулирующее влияние тинростима отмечено в отношении показателей фагоцитарной активности нейтрофилов.

Исследование уровня сывороточных иммуноглобулинов после лечения с применением тинростима свидетельствует о повышении концентрации имму- ноглобулина А (c 1,01 \pm 0,09 г/л до 1,25 \pm 0,08 г/л; $p=0,03)$ и снижении иммуноглобулина М (с $1,58 \pm$ 0,17 г/л до 1,3 \pm 0,09 г/л; $p=0,05)$. Уровень ЦИК в сыворотке крови больных снижался со 112,6 $\pm 10,1$ до 70,9 $\pm 6,9$ у. е. $(p=0,001)$, а содержание С3-, C4и С5-компонентов комплемента повышалось по сравнению с исходным и приближалось к показателям нормы.

Снижение у больных ХОБЛ содержания Т-клеточных субпопуляций лимфоцитов (как хелперов, так и супрессоров) влечет за собой нарушения регуляторных взаимоотношений иммунокомпетентных клеток, а следовательно, и продукции цитокинов. Исходный уровень про- (TNF- $\alpha$, IL-1 $\alpha$, IL-6) и противовоспалительных (IL-4) цитокинов у больных ХОБЛ существенно (5-10-кратно) превышал средние показатели нормы, что свидетельствует о системной воспалительной реакции [14, 15]. Динамика цитокинов под влиянием тинростима была следующей: снижался уровень TNF- $\alpha$ (с 52,9 \pm 5,4 пг/мл до $30,8 \pm 4,6$ пг/мл; $p<0,05)$ и уровень IL-6 (c 103,4 \pm $26,2$ пг/мл до 67,5 $\pm 25,9$ пг/мл; $p<0,05)$ при отсутствии положительной динамики отмеченных показателей в группе контроля.

Исследование показателей системы гемостаза у больных, принимавших тинростим, показало, что значение ФТ снижалось с 21,4 $\pm 2,5$ мг/\% при поступлении до $14,4 \pm 2,2$ мг / \% при выписке $(p=0,026)$, а ФА, напротив, возросла соответственно с $6,9 \pm$ $0,59 \%$ до 10,7 $\pm 1,6 \%(p=0,037)$. В процессе лечения у больных 2-й группы положительная динамика показателей ФТ и ФА отсутствовала, что свидетельствует о недостаточной эффективности проводимой терапии. Полученные данные (снижение показателей ФТ, повышение параметров ФА) указывают на то, что тинростим приводит к уменьшению тромбинемии и увеличению фибринолитического потенциала крови. Последнее способствует предотвращению отложения на стенках сосудов избытка фибрина, а следовательно, и купированию процессов фиброзирования и обструкции в бронхиальном дереве.

В результате комплексной терапии отмечалась статистически значимая положительная динамика клинического состояния пациентов, выражающаяся в редукции основных симптомов заболевания и их продолжительности. При этом на фоне приема тинростима была более выраженной регрессия характера кашля (в 2,1 раза по сравнению с 1,5 раза в группе контроля; $p<0,05)$. Кроме того, в основной группе отмечено уменышение одышки $(p<0,05)$ и продолжительности субфебрильной температуры $(p<0,05)$. В результате лечения с применением тинростима у больных ХОБЛ также регистрировалась достоверная динамика ОФВ 1 , который в 1-й группе увеличивался на 12,2\% ( $p<0,05)$, а во 2-й - на 5,6\% ( $p>0,05)$.

Таким образом, у больных ХОБЛ выявлены признаки вторичной иммунной недостаточности (нарушение клеточных и гуморальных механизмов врожденного и приобретенного иммунитета), а также латентного внутрисосудистого свертывания крови (повышение уровня активного тромбина и раст- 
воримых фибрин-мономерных комплексов на фоне снижения фибринолитического потенциала крови). Методом корреляционного анализа выявлены взаимосвязи, свидетельствующие о сопряженности нарушений в системах иммунитета и гемостаза у обследованных больных ХОБЛ, что обосновывает применение иммуномодуляторов, оказывающих влияние на обе системы, с целью коррекции обнаруженных нарушений.

Применение тинростима в комплексе с базисной терапией способствует коррекции показателей иммуного статуса больных ХОБЛ, выражающейся в повышении уровня Т-клеточного иммунитета, стимулирующем влиянии на фагоцитарную активность нейтрофилов, нормализации показателей гуморального иммунитета. Под влиянием тинростима у больных выявлено снижение показателей ФТ как маркера тромбинемии и внутрисосудистого свертывания крови, а также возрастание показателей ФА, т. е. увеличение фибринолитического потенциала крови.

Итоговым результатом включения тинростима в состав комплексной терапии больных ХОБЛ является повышение клинической эффективности лечения. Клинический эффект тинростима обусловлен его влиянием на ключевые патофизиологические процессы и связан с иммуномодулирующим, противовоспалительным действием и нормализующим влиянием на систему гемостаза. Это, в свою очередь, снижает риск прогрессирования ХОБЛ, приводит к стабилизации течения заболевания, способствует снижению гнойно-септических и коагулологических осложнений, более быстрому купированию обострений.

Учитывая полученные результаты, можно рекомендовать включение тинростима в составе в курс комплексного лечения больных ХОБЛ с целью повышения эффективности патогенетической терапии.

\section{Заключение}

Применение тинростима в курсе базисной терапии больных ХОБЛ позволяет повысить показатели клеточного и гуморального иммунитета (увеличение содержания $\mathrm{CD}^{+}-$, $\mathrm{CD}^{+}-$-лимфоцитов, усиление фагоцитарной активности нейтрофилов крови, снижение содержания ЦИК, повышение уровня компонентов комплемента, уменьшение концентрации провоспалительных цитокинов в сыворотке крови), индуцирует положительную динамику показателей системы гемостаза (снижение интенсивности гиперкоагуляции и рост фибринолитической активности крови).

С учетом иммуномодулирующих свойств и нормализующего влияния на систему гемостаза можно рекомендовать применение тинростима как средства вспомогательной терапии пациентов с ХОБЛ.

\section{Литература}

1. Зарембо И.А. Хроническая обструктивная болезнь легких: распространенность и смертность. Аллергология 2006; 1: 39-43.

2. Чучалин А.Г. (ред.). Глобальная стратегия диагностики, лечения и профилактики хронической обструктивной болезни легких (пересмотр 2006 г. ВОЗ). Пер с англ. М.: Атмосфера; 2007.

3. Кузник Б.И., Витковский Ю.А., Гаймоленко И.Н. и др. Влияние иммуномодулирующей терапии на течение острых и хронических заболеваний легких у взрослых и детей. Мед. иммунол. 2003; 5 (3-4): 301.

4. Оболонкова Н.И. Влияние иммунокоррекции с применением тималина на эффективность комплексного лечения больных хронической обструктивной болезнью легких, осложненной хроническим легочным сердцем: Автореф. дис. ... канд. мед. наук. Астрахань; 2006.

5. Дзюблик Я.А., Морозова Н.А., Яхница Т.В. и др. Особенности нарушений системы гемостаза у больных пожилого возраста, страдающих хроническими воспалительными заболеваниями легких. Укр. пульмонол. журн. 2002; 4: 58-61.

6. Cella G., Sbarai A., Mazzaro G. et al. Plasma markers of endothelial dysfunction in chronic obstructive pulmonary disease. Clin. Appl. Thromb. Hemost. 2001; 7 (3): 205-208.

7. Чесникова А.И. Особенности состояния системы гемостаза на этапах развития и прогрессирования хронического легочного сердца. Кардиоваск. тер. и профилакт. 2006; 5 (2): 50-56.

8. Voelkel N.F., Cool C.D. Pulmonary vascular involvement in chronic obstructive pulmonary disease. Eur. Respir. J. 2003; suppl. 46: 28-32.

9. Кузник Б.И., Витковский Ю.А., Сазоненко В.А. и др. Влияние тималина на иммунитет, гемостаз и уровень провоспалительных и противовоспалительных цитокинов при ожоговой болезни. Гематол. и трансфузиол. 2002; 47 (1): 17-21.

10. Ключерева Н.Н., Колесниченко Л.Р., Хамаева Ц.Б. и др. Влияние вилона, эпиталона и эпиталамина на иммунитет и гемостаз при сахарном диабете первого типа. Аллергол. и иммунол. 2005; 6 (2): 183.

11. Беседнова Н.Н., Эпштейн Л.М. Биологически активная добавка к пище тинростим (в помощь практическому врачу). Владивосток; ТИНРО-Центр; 2003.

12. Кузник Б.И., Патеюк А.В., Джулай М.А. и др. Пептидные механизмы регуляции иммунитета и гемостаза. Аллергол. и иммунол. 2005; 6 (2): 160-161.

13. Цыбиков Н.Н., Степанов А.В., Цепелев В.Л. и др. Взаимосвязь иммунитета, гемостаза и неспецифической резистентности в эксперименте и клинике. В кн.: Сборник докладов Всероссийской науч.-практ. конф. "Актуальные проблемы клинической и экспериментальной медицины". Чита; 2003: 370-371.

14. Agusti A.G.N., Noguera A., Sauleda J. et. al. Systemic effects of chronic obstructive pulmonary disease. Eur. Respir. J. 2003; 21: 347-360.

15. Gea J., Barreiro E.; Orozco-Levi M.L. Systemic inflammation in COPD. Clin. Pulm. Med. 2009; 16 (5): 233-242.

\section{Информация об авторах}

Кузнецова Татьяна Алексеевна - д. М. н., ведущий научный сотрудник лаборатория иммунологии НИИ эпидемиологии и микробиологии СО РАМН; тел.: (4232) 44-24-46; e-mail: takuznets@mail.ru

Киняйкин Михаил Федорович - К. М. Н., доцент кафедры госпитальной терапии с курсом фтизиопульмонологии Владивостокского государственного медицинского университета; тел.: (4232) 40-08-46; e-mail: 589014@bk.ru

Суханова Галина Ивановна - д. м. н., проф. кафедры госпитальной терапии с курсом фтизиопульмонологии Владивостокского государственного медицинского университета; тел.: (4232) 40-09-67

Беседнова Наталия Николаевна - акад. РАМН, директор НИИ эпидемиологии и микробиологии СО РАМН; тел.: (4232) 20-36-90; e-mail: niiem_vl@mail.ru

Поступила 15.12.09

() Коллектив авторов, 2010 удк 616.24-036.12-085.27 